\title{
Adaptasi alat ukur prosocial tendencies measure (PTM) versi bahasa Indonesia pada anak usia sekolah di Bandung
}

\begin{tabular}{l} 
Nabhilla Armadhita I*, Afra \\
I,2,3 Fakultas Psikologi, Universi \\
\hline Info Artikel \\
\hline Sejarah Artikel: \\
Diterima \\
28 Juni 2020 \\
Direview \\
28 Juni 2020 \\
Disetujui \\
20 Oktober 2020 \\
Dipublikasikan \\
I5 Januari 2021 \\
\hline Keywords: \\
Prosocial behavior, \\
validation, \\
prosocial tendencies measure
\end{tabular}

Nabhilla Armadhita I*, Afra Hafny Noer 2 , Esti Wungu ${ }^{3}$

I,2,3Fakultas Psikologi, Universitas Padjadjaran, Indonesia

\begin{tabular}{l} 
Abstrak \\
\hline Objektif: Perilaku prososial penting untuk diukur pada anak usia sekolah \\
karena sangat rentan untuk munculnya perilaku bermasalah. Tujuan dari \\
penelitian ini adalah mengadaptasi alat ukur PTM versi bahasa Indonesia \\
dengan psychometric property yang baik.
\end{tabular}

Metode: Metode penelitian kuantitatif dilakukan dalam 2 tahap yaitu studi translasi dan validasi. 373 partisipan berusia $9-12$ tahun $(M=10.31)$ dipilih melalui cluster sampling untuk mengisi kuesioner untuk mengukur validitas dan reliabilitas melalui internal consistency.

Temuan: Hasil perhitungan internal consistency alat ukur PTM menunjukkan $\alpha=0.88 \mathrm{I}$ dan hasil uji validitas dengan menggunakan CFA menunjukkan model good fit $(\mathrm{RMSEA}=0.045, \mathrm{CFI}=0.94)$. Hasil uji reliabilitas di setiap dimensi yaitu altruism $(\alpha=0.623)$, compliant $(\alpha=0.496)$, emotional $(\alpha=$ $0.582)$, public $(\alpha=0.482)$, dan dire $(\alpha=0.36 \mathrm{I})$. Hanya dimensi anonymous yang sudah reliable $(\alpha=0.729)$.

Kesimpulan: Alat ukur PTM versi bahasa Indonesia valid dan reliabel. Meskipun begitu, sebagian besar dimensi masih memiliki reliabilitas yang rendah.

\section{Adaptation of the Indonesian version of the prosocial tendencies measure (PTM) for school-age children in Bandung}

Objectives: It is important to measure prosocial behavior in school age children because it is very susceptible to problematic behavior. The aim of the present study was to adapt the Indonesian version of PTM with good psychometric properties.

Method: Quantitative research methods were carried out in 2 stages namely translation and validation studies. 373 participants ages 9-1 2 years were selected through cluster sampling to fill out a questionnaire to measure validity and reliability through internal consistency.

Findings: The results of the internal consistency of PTM showed $\alpha=0.88 \mathrm{I}$ and the results of the validity test using the CFA showed a good fit model (RMSEA = $0.045)$. The reliability test results were altruism $(\alpha=0.623)$, compliant $(\alpha=$ $0.496)$, emotional $(\alpha=0.582)$, public $(\alpha=0.482)$, and dire $(\alpha=0.36 \mathrm{I})$. Only anonymous dimensions are reliable $(\alpha=0.729)$.

Conclusions: The Indonesian version of the PTM measuring instrument is valid and reliable. Most dimensions still have low reliability.

*Alamat korespondensi:

Universitas Padjadjaran Jl. Raya Bandung Sumedang KM.2 I, Hegarmanah, Kec. Jatinangor, Kabupaten Sumedang, Jawa Barat 45363

nabhilla I2001@mail.unpad.ac.id 


\section{Pendahuluan}

Perilaku prososial adalah perilaku yang ditujukan untuk membantu atau menguntungkan orang lain atau seseorang dalam kelompok tanpa adanya antisipasi terhadap konsekuensi eksternal (Eisenberg, 1982). Berdasarkan definisi tersebut, maka perilaku prososial dimaksudkan untuk membantu orang lain tanpa mengharapkan adanya imbalan atau hadiah yang diterima setelah membantu orang lain.

Dalam banyak studi menggambarkan bahwa terdapat hubungan negatif antara perilaku prososial dengan perilaku bermasalah pada anak. Perilaku prososial berhubungan negatif dengan masalah perilaku baik masalah eksternalisasi (hiperaktif, mudah teralihkan, perilaku mengganggu) maupun internalisasi (masalah emosional seperti, kecemasan dan depresi) (Nantel-Vivier et al., 20/4). Hubungan negatif antara prososial dan perilaku bermasalah lebih kuat untuk anak-anak dengan prestasi rendah di sekolah atau tinggal di lingkungan yang kurang beruntung. Efek merugikan dari perilaku prososial rendah, terkait dengan empati rendah dan rasa bersalah dan dengan emosionalitas terbatas, pada masalah internalisasi dan eksternalisasi tampaknya diperparah dalam konteks berisiko tinggi (Flouri \& Sarmadi, 2016). Secara konseptual dan empiris, terdapat hubungan antara perilaku eksternalisasi dan perilaku prososial keduanya terkait dengan keterampilan sosiokognitif dan sosioemosi dengan cara yang menunjukkan bahwa perilaku tersebut harus berhubungan negatif satu sama lain. Sebagai contoh, ada bukti bahwa remaja yang menunjukkan regulasi emosi yang baik, perspective taking, simpati, dan keterampilan penalaran moral menunjukkan tingkat perilaku prososial yang relatif tinggi dan perilaku mengganggu dan agresif tingkat rendah (Carlo, 2006; Eisenberg et al., 2006).

Perkembangan perilaku prososial ini menjadi penting untuk diulas lebih lanjut karena menjadi kompetensi utama dalam kompetensi sosial yang sering dikaitkan dengan keberhasilan adaptasi sekolah serta hubungan dengan guru dan teman sebaya yang positif (Howes, 2000; Ladd, 1999; Pianta et al., 1995; Wentzel, I991). Beberapa bentuk perilaku prososial misalnya kesediaan untuk membantu, berbagi dan bekerja sama, dan inisiatif sosial, kemampuan untuk menanggapi tawaran sosial lainnya dan mengambil inisiatif sendiri (Rydell et al.,1997) seringkali dikaitkan dengan kemampuan sosial anak ketika di sekolah. Beberapa fenomena yang terjadi di sekolah mengenai hubungan antara masalah yang muncul dan kompetensi sosial tampak relevan. Beberapa peneliti (Dodge dan Crick, 1990) telah mengemukakan bahwa kompetensi sosial memoderasi hubungan antara perilaku bermasalah dan hubungan sosial yang bermasalah.

Oleh karena itu, perlu untuk mengetahui bagaimana perilaku prososial pada anak terutama jika dikaitkan dengan munculnya berbagai permasalahan pada anak. Perilaku prososial sendiri dapat dilakukan untuk sejumlah alasan, termasuk alasan egoistik (Eisenberg, 1982). Yang sangat penting untuk mempelajari perilaku prososial dalam banyak budaya adalah subkelompok perilaku prososial yang berlabel altruisme, kadang-kadang didefinisikan sebagai perilaku sukarela yang termotivasi secara intrinsik yang dimaksudkan untuk menguntungkan orang lain - tindakan yang dimotivasi oleh kepedulian terhadap orang lain atau oleh nilai-nilai yang diinternalisasi, tujuan, dan penghargaan diri daripada dengan harapan imbalan konkret atau sosial atau penghindaran hukuman (Eisenberg, N., Fabes, R., \& Spinrad, 2006). Akan tetapi, karena seringkali tidak mungkin untuk membedakan antara tindakan altruistik dan perilaku prososial berdasarkan motif lain, perlu untuk fokus pada domain yang lebih luas dari perilaku prososial.

Dalam buku The Roots of Prosocial Behavior in Children (Eisenberg \& Mussen, 1989), lebih menekankan pada melihat perkembangan kecenderungan untuk berperilaku prososial (prosocial tendencies). Hal ini disebabkan karena ketika seorang anak menunjukkan salah satu bentuk yang mengarahkan ke perilaku prososial maka akan memprediksikan munculnya perilaku prososial di masa mendatang. Maka, perlu adanya sebuah alat ukur untuk melakukan screening terhadap anak untuk melihat bagaimana perilaku prososial mereka. Alat screening ini dimaksudkan agar dapat menjadi deteksi dini bagi anak ketika perilaku prososial yang ditunjukkan dapat dikategorikan rendah dan diiringi dengan adanya keluhan-keluhan dari perilaku anak maka dapat menjadi tolak 
ukur untuk dilakukannya pemeriksaan psikologi lebih lanjut bagi anak untuk mengetahui apakah terdapat permasalahan perilaku pada anak atau tidak. Alat screening ini sendiri nantinya akan dapat digunakan baik oleh orang tua, guru, maupun pihak-pihak terkait yang berhubungan dengan anak untuk melihat bagaimana kecenderungan munculnya perilaku prososial pada anak.

Untuk mengukur perilaku prososial sendiri dapat diklasifikasikan ke dalam setidaknya dua kategori, yang menilai perilaku prososial global atau perilaku yang menilai perilaku prososial dalam situasi tertentu. Ukuran perilaku prososial yang paling umum adalah yang dirancang untuk menilai perilaku prososial secara global. Ukuran perilaku prososial global didefinisikan sebagai tindakan yang menilai kecenderungan pribadi untuk menunjukkan sejumlah perilaku prososial di seluruh konteks dan motif (Green et al., 1994; Johnson et al., 1989; Rushton et al., 1981; Weir dan Duveen, 198I). Kategori kedua ukuran perilaku prososial adalah penilaian perilaku prososial dalam konteks tertentu. Penilaian ini sering kali merupakan pengamatan perilaku untuk membantu peluang (misalnya, mengambil barang yang dijatuhkan, menyumbang uang) yang biasanya dirancang untuk studi tertentu, seringnya pada studi eksperimental.

Perilaku prososial global atau ukuran kompetensi sosial terbatas karena para peneliti sebelumnya telah menunjukkan bahwa ada berbagai jenis perilaku prososial dan bahwa masing-masing jenis ini memiliki korelasi pribadi dan situasional yang berbeda. Beberapa peneliti telah menyajikan bukti bahwa ada perbedaan antara individu yang membantu orang lain ketika mereka diminta dan mereka yang melakukannya secara spontan (Eisenberg-Berg et al., 198I). Penggunaan penilaian perilaku prososial secara global, bukan spesifik situasi, telah disajikan sebagai satu penjelasan yang mungkin untuk hubungan yang sebelumnya lemah dan tidak konsisten antara variabel sosiokognitif dan sosioemosional dan perilaku prososial (Carlo et al., 199/b; Kurdek, 1978; Underwood dan Moore, 1982). Dengan demikian, ukuran global perilaku prososial mungkin membatasi kemampuan peneliti untuk menangani pertanyaan konseptual khusus berkenaan dengan korelasi perilaku prososial.

Sebaliknya, ukuran perilaku prososial spesifik pada situasi tertentu berguna dalam menjawab pertanyaan konseptual spesifik tentang pengembangan dan berkorelasi dengan berbagai jenis perilaku prososial. Untuk itu, Carlo \& Randall (2002) mengembangkan sebuah alat ukur untuk mengukur bagaimana kecenderungan perilaku prososial secara spesifik pada remaja akhir yang dinamakan prosocial tendencies measure (PTM). Carlo \& Randall sendiri berpendapat bahwa belum ada alat ukur berbasis paper-and-pencil yang mengukur perilaku prososial spesifik terutama pada remaja. Akhirnya, mereka pun menurunkan beberapa bentuk perilaku prososial berdasarkan pada penelitian-penelitian sebelumnya, yaitu:

I) Altruism: membantu secara sukarela yang dimotivasi terutama oleh kepedulian terhadap kebutuhan dan kesejahteraan orang lain, sering disebabkan oleh simpati dan norma/prinsip yang diinternalisasi yang konsisten dengan membantu orang lain (Eisenberg \& Mussen, 1989).

2) Compliant: membantu orang lain dalam menanggapi permintaan verbal atau nonverbal (Eisenberg-Berg et al., 198I).

3) Emotional: orientasi untuk membantu orang lain dalam keadaan yang membangkitkan emosi. Beberapa situasi menolong dapat dikarakteristikan sebagai sangat emosional (Carlo \& Randall, 2002)

4) Public: Perilaku prososial yang dilakukan di depan orang banyak cenderung termotivasi, setidaknya sebagian, oleh keinginan untuk mendapatkan persetujuan dan penghargaan orang lain (misalnya, orang tua, teman sebaya) dan meningkatkan harga diri seseorang (Carlo \& Randall, 2002)

5) Anonymous: membantu tanpa adanya pengetahuan tentang siapa yang membantu (Carlo \& Randall, 2002)

6) Dire: membantu dalam krisis atau situasi darurat (Carlo \& Randall, 2002) 
Alat ukur PTM ini sudah pernah diadaptasi ke dalam beberapa bahasa yaitu Bahasa Argentina (Richaud et al., 20I2) pada anak usia sekolah dan remaja, Bahasa Iran (Azimpour et al., 20I2) pada mahasiswa, Bahasa Spanyol (Mestre et al., 2015) pada remaja, Bahasa Lituania (Šukys \& Šukienė, 20 I5) pada remaja, Bahasa Portugis (Pastorelli et al., 2016) pada anak usia sekolah menengah akhir, dan Bahasa Jerman (Rodrigues et al., 2017) pada mahasiswa. Akan tetapi, masih sedikit yang mengadaptasi alat ukur ini pada anak usia sekolah dasar, bahkan hanya dilakukan di Argentina. Sebagian besar penelitian untuk mengadaptasi alat ukur ini lebih banyak dilakukan pada remaja baik yang duduk di bangku sekolah menengah maupun mahasiswa.

Selain itu, PTM ini sudah beberapa kali digunakan di Indonesia untuk dapat melihat perkembangan perilaku prososial yang dihubungkan dengan disiplin dan empati (Rayesa \& Nu'man, 20 I5), perilaku prososial yang dikaitkan dengan fungsi sosioemosional (Eisenberg et al., 2009), dan pengaruh eksklusi sosial terhadap kecenderungan perilaku prososial (Hamonangan \& Ariyanto, 2014). Akan tetapi, penggunaan PTM dalam penelitian-penelitian sebelumnya di Indonesia hanya melalui proses translasi dan adaptasi bahasa tanpa mencantumkan hasil pengukuran reliabilitas dan validitasnya (Eisenberg et al., 2009; Hamonangan \& Ariyanto, 20I4; Rayesa \& Nu'man, 20 I5). Oleh karena itu dalam penelitian ini, peneliti ingin melakukan proses adaptasi berdasarkan pedoman dari International Test Commission (ITC) agar alat ukur PTM ini dapat digunakan sebagai acuan untuk melakukan deteksi dini mengenai kecenderungan perilaku prososial.

Dalam penelitian ini, peneliti akan meneliti pada usia sekolah akhir dikarenakan pada usia ini, munculnya perilaku-perilaku bermasalah lebih rentan terjadi yang menyebabkan kemungkinan munculnya berbagai gangguan perilaku di masa mendatang. Penelitian-penelitian menunjukkan bahwa penarikan dan rasa malu, termasuk di antara masalah internalisasi, juga terkait dengan penerimaan teman sebaya yang rendah (Newcomb et al., 1993), terutama untuk an ak-anak dari sekitar usia sembilan tahun dan lebih tua (Gresham dan Elliot, 1987; Rubin et al., 1998). Dengan demikian, masalah internalisasi dan eksternalisasi umum terjadi di masa kanak-kanak tengah, mereka cukup stabil (terutama masalah eksternalisasi), dan sering digabungkan dengan prestasi sekolah rendah dan hubungan teman sebaya yang buruk. Hal ini jelas penting untuk mengidentifikasi faktor-faktor di dalam dan di sekitar anak yang dapat mempengaruhi munculnya masalah pada anak.

Selain ini beberapa penelitian pun menunjukkan bahwa berbagai aspek dalam perilaku orang tua (gaya pengasuhan, praktik, dan empati) memiliki hubungan yang berbeda sesuai dengan jenis perilaku prososial yang muncul (Richaud, Mesurado, \& Lemos, 2012). Altruisme tampaknya menjadi satu-satunya perilaku prososial yang secara intrinsik termotivasi, karena dikaitkan dengan empati dan penerimaan orangtua dan terkait negatif dengan semua praktik pengasuhan. Sebaliknya, perilaku prososial public dikaitkan dengan kontrol patologis dari ibu, yaitu, dilakukan untuk menghindari hukuman atau mendapatkan persetujuan, dan terkait dengan praktik pengasuhan sebagai hadiah material yaitu, perlu penguatan eksternal untuk melakukan sesuatu. Meskipun perilaku prososial anonymous mungkin tampak mirip dengan altruisme, yang pertama sebenarnya dimotivasi secara ekstrinsik dengan harapan menerima hadiah materi. Perilaku prososial anonymous berkorelasi positif hanya dengan praktik pengasuhan, pengalaman belajar ibu, dan imbalan materi.

Selain itu, tidak ada tindakan orang tua yang terkait dengan Compliant, dan hanya praktik pembelajaran pengalaman orang tua yang dikorelasikan dengan Dire dan Emotional. Namun, ketika tiga perilaku prososial ini (Compliant, Dire, dan Emotional) dipelajari bersama, ditemukan bahwa kontrol patologis dari ibu, otonomi ekstrim dari ayah, perhatian empatik ibu, dan pengambilan perspektif ayah adalah semua prediktor penting. Karena itu, dihipotesiskan bahwa kontrol ketat dari ibu dan permisif dari ayah yang dikombinasikan dengan kepedulian orang tua terhadap orang lain dapat menyebabkan ketidakstabilan emosional pada anak. Perilaku prososial mungkin didasarkan pada penghindaran perasaan ketidaknyamanan negatif ketika dihadapkan dengan situasi emosional yang kuat karena kebutuhan atau krisis orang lain (Richaud et al., 20I2).

Dengan demikian, perilaku prososial spesifik pada dasarnya mulai muncul pada anak di usia dini terutama dikaitkan dengan tindakan yang dilakukan oleh orang tua terhadap anaknya. Oleh karena 
itu, menjadi penting untuk mengetahui bentuk-bentuk perilaku prososial yang dimunculkan anak di usia sekolah, tidak hanya memfokuskan pada usia dewasa. Ditambah lagi seperti yang sudah dijelaskan sebelumnya, beberapa peneliti (Dodge dan Crick, 1990) telah mengemukakan bahwa kompetensi sosial memoderasi hubungan antara perilaku bermasalah dan hubungan sosial yang bermasalah. Sehingga, penting untuk mengetahui bagaimana kompetensi sosial yang dilihat melalui perilaku prososial anak yang akan mempengaruhi perilaku bermasalah pada anak.

Oleh karena itu,Tujuan dari penelitian ini adalah untuk mengadaptasi alat ukur Prosocial Tendencies Measures (PTM) versi Bahasa Indonesia dengan psychometric property yang baik.

\section{Metode}

Metode penelitian yang digunakan dalam penelitian yaitu metode penelitian kuantitatif noneksperimental yang dibagi menjadi 2 tahapan besar yaitu tahap pertama adalah studi translasi dan tahap kedua adalah studi validasi. Tahapan penelitian yang akan dilakukan diambil dari pedoman adaptasi tes yang dikembangkan oleh International Test Commission (ITC). Dalam tahapan tersebut terdapat 18 pedoman yang disusun dalam enam topik besar. Dalam penelitian ini, 2 topik besar utama yaitu pre-condition dan pengembangan tes akan dilakukan pada studi I, sedangkan 4 topik besar lainnya yaitu confirmation, administration, scale score \& interpretation, dan documentation akan dilakukan pada studi 2.

Sampel dalam penelitian ini berjumlah 373 partisipan berusia $9-12$ tahun $(M=10.31$, laki-laki $=$ $50.7 \%$ ). Partisipan merupakan anak-anak berusia 9- 12 tahun yang menempuh pendidikan di kelas 46 SD pada Sekolah Dasar Negeri di Kota Bandung yang dipilih melalui teknik sampling cluster sampling. Secara total dipilih 4 sekolah dasar negeri yang mewakili I kecamatan pada masing-masing rayon di Kota Bandung (Bandung utara, timur, selatan, dan barat).

Pengukuran dalam penelitian ini menggunakan alat ukur Prosocial Tendencies Measure (PTM) yang dikembangkan oleh Carlo \& Randall (2002) kemudian ditranslasi ke dalam bahasa Indonesia melalui prosedur forward \& backward translation oleh Pusat Studi Bahasa Universitas Padjadjaran. Alat ukur PTM mengukur kecenderungan perilaku prososial pada enam subskala yaitu: altruism (5 item), perilaku prososial anonymous (5 item), perilaku prososial compliant (2 item), perilaku prososial dire (3 item), perilaku prososial emotional (4 item), dan perilaku prososial public (4 item). Alat ukur ini memiliki 5 skala Likert yaitu I (sangat tidak menggambarkan diri saya) sampai 5 (sangat menggambar diri saya.

Teknik analisis data yang dilakukan dalam penelitian ini yaitu mengukur reliabilitas dan validitas alat ukur PTM versi bahasa Indonesia. Reliabilitas diukur melalui internal consistency dengan menghitung cronbach alpha melalui bantuan program SPSS Statistics 20 dan melalui test-retest yang dilakukan pada 4 I partisipan. Sedangkan bukti-bukti validitas yang digunakan dalam penelitian ini yaitu evidence based on test content melalui telaah mendalam dari ahli psikologi, evidence based response process melalui thinking aloud protocol dengan menggunakan cognitive interview, evidence based on internal structure dengan CFA (Confirmatory Factor Analysis) dengan menggunakan program LISREL 8.80, dan evidence based on relations to other variables dengan membandingkan skor partisipan pada alat ukur PTM dengan alat ukur Strength Difficulties Questionnaire (SDQ).

Prosedur penelitian yang dilakukan yaitu melakukan perizinan kepada pihak-pihak terkait yaitu kepada Dinas Pendidikan Kota Bandung dan sekolah-sekolah yang menjadi target sampel. Setelah mendapat persetujuan, Peneliti mendatangi sekolah dan memberikan informed consent kepada masing-masing anak untuk diisi oleh orang tua atau wali yang bertanggung jawab terhadap anak di rumah. Setelah mendapatkan persetujuan dari orang tua atau wali melalui informed consent yang telah diisi, peneliti melakukan pengumpulan data terhadap anak berupa mengisikan kuesioner.Pengisian kuesioner dilakukan di dalam satu kelas yang telah dirancang posisi duduknya agar anak dapat duduk sendiri dengan tidak saling menyontek atau melihat jawaban temannya satu sama lain dengan peneliti memandu proses pengisian kuesioner di depan kelas.Peneliti memberikan 
instruksi di depan kelas kepada seluruh partisipan kemudian partisipan diminta untuk mengisi lembar kuesioner selama 10-15 menit.

\section{Hasil}

Penelitian dilakukan 4 (empat) sekolah dasar negeri di kota Bandung yang dipilih berdasarkan cluster sampling didapatkan jumlah sampel sebesar 373 partisipan yang berusia antara $9-12$ tahun $(M=10.3 \mathrm{I})$. Partisipan terdiri dari 189 orang berjenis kelamin laki-laki $(50.7 \%)$ dan 184 orang berjenis kelamin perempuan $(49.3 \%)$.

\section{Tabel I}

Gambaran Partisipan Berdasarkan Wilayah Kota Bandung

\begin{tabular}{|c|c|c|c|c|}
\hline Zona & Wilayah & Sekolah & $\begin{array}{c}\text { Jumlah } \\
\text { Partisipan }\end{array}$ & Persentase \\
\hline $\bar{A}$ & Bandung Utara & SDN II3 B & 103 & $27.6 \%$ \\
\hline B & Bandung Timur & SDN 267 GBA & 85 & $22.8 \%$ \\
\hline C & Bandung Selatan & SDN 235 LK & 69 & $18.5 \%$ \\
\hline$D$ & Bandung Barat & SDN 016 DCP & 116 & $31.1 \%$ \\
\hline & Total & & 373 & $100 \%$ \\
\hline
\end{tabular}

Hasil uji reliabilitas alat ukur PTM dengan cronbach's alpha untuk keseluruhan dimensi yaitu dengan 23 item, didapatkan $\alpha=0.8 \mathrm{II}$ maka dapat terlihat bahwa $\alpha>0.7$ sehingga alat ukur PTM dapat diandalkan. Kemudian untuk hasil uji reliabilitas setiap dimensi didapatkan bahwa hanya dimensi anonymous yang dapat diandalkan dengan $\alpha=0.729$, sedangkan untuk dimensi lainnya tidak dapatkan diandalkan karena memiliki nilai $\alpha<0.70$.

\section{Tabel 2}

Hasil Uji Reliabilitas Cronbach Alpha Alat Ukur PTM

\begin{tabular}{cccc}
\hline Dimensi & Cronbach's Alpha & Jumlah Item & Kriteria \\
\hline Altruism & 0.623 & 5 & Tidak Dapat diandalkan \\
Compliant & 0.496 & 2 & Tidak Dapat diandalkan \\
Emotional & 0.582 & 4 & Tidak Dapat diandalkan \\
Public & 0.482 & 4 & Tidak Dapat diandalkan \\
Anonymous & 0.729 & 5 & Dapat diandalkan \\
Dire & 0.361 & 3 & Tidak Dapat diandalkan \\
PTM (overall) & 0.811 & 23 & Dapat diandalkan \\
\hline
\end{tabular}

Selain dengan cronbach alpha, uji reliabilitas test-retest dilakukan dengan mempertimbangkan konsistensi dari hasil tes ketika tes tersebut diadministrasikan untuk waktu yang berbeda. Semakin tinggi korelasi positifnya, maka semakin tinggi tingkat reliabilitas alat ukur yang digunakan (Kaplan \& Saccuzzo, 2005). Pada penelitian ini metode test-retest dilakukan pada 4I partisipan di 2 sekolah yaitu 22 partisipan kelas 5 SDN 267 GBA dan 19 partisipan kelas 5 SDN 016 DCP. Pengetesan dilakukan dengan jarak 2-4 minggu setelah pengetesan awal. Didapatkan bahwa dimensi compliant memiliki reliabilitas yang tinggi dengan $\rho=0.708$. Sedangkan untuk dimensi altruism, emotional, dan public memiliki reliabilitas sedang dan untuk dimensi anonymous dan dire memiliki reliabilitas yang rendah. 


\section{Tabel 3}

Hasil Uji Reliabilitas Test-Retest Alat Ukur PTM

\begin{tabular}{cccc}
\hline Dimensi & $\boldsymbol{\rho}$ & Jumlah Item & Kriteria \\
\hline Altruism & 0.653 & 5 & Reliabilitas Sedang \\
Compliant & 0.708 & 2 & Reliabilitas Tinggi \\
Emotional & 0.456 & 4 & Reliabilitas Sedang \\
Public & 0.501 & 4 & Reliabilitas Sedang \\
Anonymous & 0.317 & 5 & Reliabilitas Rendah \\
Dire & 0.225 & 3 & Reliabilitas Rendah \\
\hline
\end{tabular}

Bukti validitas yang pertama dilakukan oleh peneliti yaitu melakukan expert review atau proses penelaahan alat ukur PTM yang telah melalui proses translasi forward-backward kepada ahli yang memiliki pengalaman, pengetahuan, maupun kapasitas dalam memahami konstruk maupun bahasa yang dipakai di dalam alat ukur. Ahli yang melakukan penelaahan merupakan dua orang ahli psikologi perkembangan yang juga seorang psikolog klinis anak dan remaja. Hasil validitas ini digunakan untuk melihat kesesuaian isi dalam setiap item di alat ukur PTM dengan konstruk yang diukur yaitu perilaku prososial. Para ahli pun sepakat bahwa keseluruhan item yang sudah diubah ke bahasa Indonesia sudah sesuai dengan dimensi-dimensi yang diukur dari setiap itemnya. Hanya saja, perlu untuk mengubah dan menghilangkan beberapa kata dalam beberapa item agar lebih memudahkan untuk dipahami oleh target populasi yang akan dijadikan partisipan dalam penelitian ini.

Setelah mendapatkan telaah dari ahli, peneliti mengumpulkan bukti validitas kedua berdasarkan proses target populasi dalam memahami keseluruhan isi dari alat ukur PTM. Peneliti melakukan uji coba awal sebanyak dua kali, yaitu uji coba pertama melibatkan 3 orang anak berusia 10 - I I tahun (kelas 4-6 SD) dan uji coba kedua melibatkan 4 orang anak berusia 10-12 tahun (kelas 5-6 SD). Setiap anak diminta untuk membacakan instruksi dan setiap item dengan suara lantang kemudian menjelaskan maksud dari setiap item dengan bahasanya sendiri. Setelah itu, peneliti menanyakan apakah ada kata atau kalimat yang sulit dipahami oleh anak. Jika anak menyebutkan ada kata/kalimat yang tidak ia pahami, maka peneliti menanyakan adakah kata yang dapat digunakan agar ia lebih dapat memahami maksud dari item yang diberikan kepadanya. Setiap anak mengatakan masih ada beberapa kata dalam sebagian item yang sulit untuk dipahami. Oleh karena itu, peneliti mencoba untuk melakukan pemilihan kata untuk menghasilkan diksi atau pilihan kata yang tepat sesuai dengan konteks dan pemahaman anak berdasarkan kaidah penulisan Bahasa Indonesia (Kementerian Pendidikan dan Kebudayaan Republik Indonesia, 2016, 2020).

Bukti validitas yang juga digunakan dalam alat ukur ini yaitu analisis struktur internal dengan CFA (Confirmatory Factor Analysis). Untuk mengetahui penilaian pada CFA menggunakan pengujian model fit (Hair Jr et al., 20 I 4). Uji model fit dilakukan untuk menentukan apakah model yang diestimasi fit dengan data Evaluasi model fit dilakukan dari beberapa kriteria yaitu penilaian model secara keseluruhan (model as a whole) dan signifikansi estimasi parameter tiap item. Penelitian menemukan bahwa untuk mengetahui model fit, dapat melihat beberapa kriteria penilaian, yaitu cutoff mendekati .95 untuk TLI, BL89, CFI, RNI, dan Gamma Hat; nilai cutoff mendekati 0,90 untuk Mc; nilai cutoff mendekati 0,08 untuk SRMR; dan nilai cutoff mendekati .06 untuk RMSEA diperlukan sebelum kita dapat menyimpulkan bahwa ada kesesuaian yang relatif baik antara model yang dihipotesiskan dan data yang diamati (Hu \& Bentler, 1999). Hasil perhitungan didapatkan bahwa model alat ukur PTM ini fit atau dapat dikatakan bahwa item-item di dalam alat ukur PTM mengukur konstruk dengan tepat.Untuk melihat hasil uji validitas menggunakan CFA dapat merujuk pada Tabel 4. 


\section{Tabel 4}

Hasil Uji Validitas Alat Ukur PTM

\begin{tabular}{ccc}
\hline Kriteria & Indeks & Ukuran Fit Indeks \\
\hline RMSEA & 0.045 & Good Fit \\
CFI & 0.94 & Good Fit \\
IFI & 0.94 & Good Fit \\
Standardized RMR & 0.062 & Good Fit \\
\hline
\end{tabular}

Bukti validitas terakhir yang dilakukan yaitu dengan membandingkan dengan variabel lain yaitu dengan menggunakan alat ukur Strengths \& Difficulties Questionnaire (SDQ). Kuesioner Kekuatan dan Kesulitan (SDQ) adalah kuesioner satu halaman untuk menilai penyesuaian psikologis anak-anak dan remaja (Goodman, 200I). Kuesioner ini dapat diselesaikan oleh orang tua atau guru dari anak usia 3-16 tahun dan oleh anak usia I I - 16 tahun sendiri. SDQ terdiri dari 25 item yang dialokasikan pada lima subskala. Keempat subskala termasuk ke dalam kelompok subskala Difficulties (kesulitan), yaitu subskala emotional symptom, subskala conduct problem, subskala hyperactivity-inattention, dan subskala peer problem. Sedangkan subskala yang kelima termasuk dalam kelompok subskala Strengths (kekuatan), yaitu subskala prosocial (Department of Health and Ageing, 2002).

Berdasarkan dari hasil korelasi dengan $\alpha=0.05$, maka dapat terlihat bahwa dimensi-dimensi dalam PTM yaitu altruism, compliant, public, emotional, dan dire memiliki korelasi dengan dimensi prososial dalam alat ukur SDQ. Hal ini menunjukkan bahwa dimensi dalam alat ukur PTM memiliki hubungan dengan dimensi prososial di dalam alat ukur PTM karena sama-sama mengukur mengenai perilaku prososial meskipun dengan korelasi yang rendah $(\rho<0.4)$. Sedangkan hubungan antara dimensidimensi PTM dengan dimensi-dimensi dalam SDQ lainnya justru menunjukkan tidak terdapat hubungan.

\section{Tabel 5}

Hasil Korelasi Alat Ukur PTM dengan Alat Ukur SDQ

\begin{tabular}{|c|c|c|c|c|c|c|}
\hline \multirow{2}{*}{\multicolumn{2}{|c|}{ Correlation Coefficient }} & \multicolumn{5}{|c|}{ Strengths \& Difficulties Questionnaire (SDQ) } \\
\hline & & $\begin{array}{l}\text { Emotional } \\
\text { Symptoms }\end{array}$ & $\begin{array}{l}\text { Conduct } \\
\text { Problem }\end{array}$ & Hyperactivity & $\begin{array}{c}\text { Peer } \\
\text { Problem }\end{array}$ & Prosocial \\
\hline \multirow{6}{*}{$\frac{\sum}{i}$} & Altruism & 0.202 & 0.070 & 0.228 & 0.093 & $0.261^{*}$ \\
\hline & Compliant & -0.100 & 0.053 & -0.066 & -0.114 & $0.298 *$ \\
\hline & Public & 0.127 & -0.062 & 0.050 & 0.051 & $0.264 *$ \\
\hline & Emotional & 0.139 & -0.027 & 0.064 & 0.201 & $0.286 *$ \\
\hline & Anonymous & 0.053 & 0.031 & 0.029 & 0.158 & 0.215 \\
\hline & Dire & 0.153 & 0.064 & $0.276 *$ & 0.019 & $0.429 *$ \\
\hline
\end{tabular}

*Korelasi signifikan dengan $\alpha=0.05$

Setelah melakukan uji reliabilitas dan validitas, prosedur selanjutnya yaitu menghubungkan skala skor dari versi bahasa tes yang berbeda. Analisis data yang digunakan yaitu dengan menganalisis item menggunakan item discrimination. Item discrimination dapat digunakan untuk menentukan item mana yang paling baik untuk mengukur suatu konstruk atau konten yang sedang diteliti (Friedenberg, 1995). Item discrimination dapat dilakukan dengan cara menghitung korelasi item total. Cara melakukan analisis item adalah dengan melihat hasil corrected item-total correlation dalam perhitungan reliabilitas dengan menggunakan program SPSS Statistics 20. Analisis item untuk menentukan item mana yang dapat digunakan, perlu diperbaiki dan harus dibuang (Ebel \& Frisbie, 1991). Hasil uji analisis item dapat dilihat pada tabel 6. hasil analisis item menunjukkan alat ukur PTM memiliki 4 item yang tergolong marginal item atau perlu untuk direvisi. Item-item tersebut yaitu item no.I pada dimensi public, item no. 8 dan 22 pada dimensi anonymous, dan item no. 23 
pada dimensi altruism. Sedangkan item-item lainnya sudah tergolong baik dan sangat baik sehingga dapat digunakan di dalam alat ukur PTM ini karena sudah dapat mengukur sesuai dengan dimensi dan konstruk yang diukurnya yaitu perilaku prososial.

\section{Tabel 6}

Hasil Uji Analisis Item Alat Ukur PTM

\begin{tabular}{cccc}
\hline Nilai R & Klasifikasi & No Item & Jumlah Item \\
\hline- & Poor & - & 0 \\
$0.280-0.293$ & Marginal & $1,8,22,23$ & 4 \\
$0.300-0.396$ & Reasonably Good & $2,3,4,5,6,7,9,10$, & 14 \\
$0.407-0.472$ & Very Good & $15,12,13,14,16,18,20,21$ & 5 \\
\hline & Total & & 23 \\
\hline
\end{tabular}

Dalam adaptasi alat ukur PTM, item-item dalam dimensi altruism merupakan item-item negatif sehingga dapat proses skoring alat ukur, skala negatif harus diubah terlebih dahulu menjadi skala positif. Akan tetapi, berdasarkan hasil pengolahan data didapatkan bahwa ternyata dimensi altruism tidak dimaknai secara negatif oleh partisipan sehingga justru dianggap sebagai item positif sama seperti dimensi-dimensi lainnya. Dalam hasil analisis terhadap item-item pun ada beberapa item yang dimaknai mirip dengan item dalam dimensi altruism. Untuk lebih melihat sejauh mana korelasi antar dimensi maka dilakukan uji interkorelasi antar dimensi dalam alat ukur PTM untuk melihat keterkaitannya masing-masing yang dapat terlihat pada Tabel 7.

Secara umum, dimensi PTM secara positif dan sederhana saling terkait satu sama lain namun dimensi public ternyata paling berhubungan secara positif dengan dimensi altruism. Selain itu, ditemukan punya bahwa dimensi dire memiliki hubungan secara positif dengan dimensi emotional.

\section{Tabel 7}

Inter-korelasi antar Dimensi Alat Ukur PTM

\begin{tabular}{ccccccc}
\hline & Altruism & Compliant & Emotional & Public & Anonymous & Dire \\
\hline Altruism & - & & & & & \\
Compliant & $0.153^{*}$ & & & & & \\
Emotional & $0.230^{*}$ & $0.419^{*}$ & & & & \\
Public & $0.531^{*}$ & $0.213^{*}$ & $0.314^{*}$ & & & \\
Anonymous & $0.194^{*}$ & $0.282^{*}$ & $0.403^{*}$ & $0.228^{*}$ & & \\
Dire & $0.388^{*}$ & $0.363^{*}$ & $0.412^{*}$ & $0.392^{*}$ & $0.257^{*}$ & \\
\hline *Korelasi signifikan & & & &
\end{tabular}

*Korelasi signifikan dengan $\alpha=0.05$

Hasil penelitian terdiri dari statistika hasil uji hipotesis dan analisa tambahan yang relevan kemudian dianalisis secara kritis (3-5 halaman) dipaparkan secara berurutan atau terpadu. Paparan bagian hasil berisi hasil analisis data. Jika ada tabel/ gambar berisi paparan hasil analisis yang sudah bermakna dan mudah dipahami maknanya secara tepat. Tabel/ gambar tidak berisi data mentah yang masih dapat atau harus diolah. Untuk hasil penelitian eksperimen perlu dipaparkan hasil analisis data mulai pretest-posttest-follow up, termasuk penjelasan singkat dan tepat terkait hasil intervensi. 


\section{Pembahasan}

Dimensi-dimensi dalam alat ukur PTM ini tidak reliable, dapat disebabkan karena korelasi antar item di dalam satu dimensi didapatkan memiliki nilai yang sangat kecil. Seperti contoh item 6 dan item 9 pada dimensi dire didapatkan memiliki nilai korelasi yaitu 0.193, begitu pula item 9 dengan item 14 didapatkan memiliki nilai koefisien korelasi $\rho=0.153$. Berdasarkan kriteria Guilford ( 979 ) jika $\rho<0,2$ maka tidak ada hubungan, maka dapat dilihat bahwa item-item di dalam dimensi dire tidak memiliki hubungan sehingga menyebabkan nilai koefisien alpha pun kecil dan dianggap tidak dapat diandalkan. Hal ini sejalan pula pada dimensi lain yaitu dimensi altruism, compliant, emotional, dan public yaitu item-item di dalam dimensi ternyata memiliki hubungan yang rendah atau bahkan tidak memiliki hubungan antar item yang diukurnya.

Dimensi anonymous sebelumnya terlihat memiliki reliabilitas yang baik namun justru dalam metode test-retest ini memiliki reliabilitas yang rendah. Hal ini dapat disebabkan karena adanya perubahan pemahaman pada partisipan ketika kembali mengisi alat ukur PTM, ataupun adanya perubahan karakteristik lainnya yang muncul selama proses berlangsung. Hal ini dimungkinkan terjadi ketika partisipan mungkin memiliki pemahaman yang berbeda saat pertama kali mengisi dibandingkan dengan mengisi pada saat kedua kali. Untuk itu, perlu untuk memastikan bahwa setiap partisipan memiliki pemahaman yang sama untuk setiap item yang mereka dapatkan di dalam alat ukur ini.

Jika dilihat berdasarkan perkembangan perilaku prososial, seiring bertambahnya usia, semakin tinggi pula kemungkinan untuk munculnya perilaku prososial (Eisenberg, N., Fabes, R., \& Spinrad, 2006). Akan tetapi, dalam beberapa keadaan, bertambahnya usia anak menjadikan mereka lebih membeda-bedakan mengenai siapa yang harus ditolong dan menunjukkan penurunan perilaku prososial. Pada saat yang sama, semakin bertumbuhnya pemahaman sosiokognitif, anak yang berusia lebih besar mungkin merasakan lebih banyak peluang untuk melakukan perilaku prososial (Eisenberg, N., Spinrad \& Knafo-Noam, 20I5).

Hasil analisis item pun menunjukkan bahwa item I pada dimensi public, item 8 dan 22 pada dimensi anonymous, serta item 23 pada dimensi altruism masih tergolong marginal item atau berarti itemitem tersebut masih perlu untuk diperbaiki dari sisi bahasa maupun konteks agar lebih dapat sesuai mengukur dimensi-dimensinya.

Dari hasil yang reliabilitas dan analisis item tersebut, terlihat bahwa terdapat hasil yang sama tapi hasil reliabilitas dimensi altruism, public, dan anonymous yang belum cukup baik dapat dipengaruhi oleh item-item yang masih perlu untuk diperbaiki. Masih adanya beberapa item yang sulit untuk dipahami dapat dipengaruhi oleh perkembangan sosiokognitif anak-anak yang berusia $9-12$ tahun ini yang masih terus berkembang. Bagi beberapa ahli teori, sumber utama peningkatan perilaku prososial dan altruisme di seluruh usia adalah perkembangan sosiokognitif, termasuk memahami dan menguraikan emosi orang lain, proses evaluatif (mengevaluasi perilaku dan situasi dalam hal standar moral), dan proses perencanaan (Eisenberg, N., Fabes, R., \& Spinrad, 2006).

Selain itu, keterbatasan penelitian juga terletak pada proses telaah alat ukur PTM yang belum mempertimbangkan adanya proses perubahan bahasa dari alat ukur PTM yang sebelumnya digunakan pada populasi berusia remaja akhir menuju dewasa awal menjadi populasi anak berusia 9- 12 tahun. Proses perubahan ini memang dirasakan cukup berdampak pada proses adaptasi yang dilakukan. Banyak kata-kata yang diubah dari kalimat aslinya agar dimungkinkan dapat dipahami oleh target populasi dalam penelitian ini. Selain itu, dalam pengambilan data, masih banyak anakanak yang belum memahami kata-kata dalam setiap item yang diberikan sehingga perlu untuk dijelaskan lebih lanjut atau diberikan penjelasan dengan bahasa yang lebih sederhana agar lebih mudah untuk dipahami oleh anak-anak. Banyak item yang masih dipertanyakan maknanya oleh anak, terutama item-item yang berada di dalam dimensi altruism.

Dimensi altruism merupakan dimensi yang berisikan item-item negatif yang memang dimaksudkan agar partisipan yang mengisi alat ukur PTM tidak langsung mengisi berdasarkan standar sosial yang berlaku namun berdasarkan dengan apa yang ia lakukan. Dalam penelitian ini, ternyata partisipan 
anak-anak merasa kesulitan untuk memahami makna dari setiap item sehingga item-item yang seharusnya bermakna negatif justru dilihat sebagai item positif yang serupa dengan item-item dalam dimensi lain. Oleh karena itu, proses skoring dimensi altruism tidak membalik skor negatif menjadi positif dikarenakan proses pemahaman dari partisipan yang tidak sesuai dengan harapan dimensi yang diukurnya. Item-item dalam dimensi altruism lebih mengukur motivasi atau alasan di balik perilaku prososial tetapi dimensi-dimensi lain lebih langsung mengukur perilaku atau situasi saat perilaku prososial dilakukan sehingga memang membutuhkan proses dan pemahaman yang lebih sulit. Di sisi lain beberapa penelitian menunjukkan bahwa item-item dalam dimensi altruism nampaknya serupa dengan penalaran prososial (moral) atau setidaknya beberapa aspek penalaran prososial. Jika dilihat dari item-item yang memang lebih mirip dengan penalaran prososial daripada perilaku prososial maka harus pula mempertimbangkan perbedaan penalaran moral (prososial) di berbagai budaya (Gibbs et al., 2007).

Proses inilah yang membutuhkan adanya telaah lebih mendalam terkait perbedaan budaya dan bahasa yang terjadi di Indonesia di dalam pemaknaan setiap item yang diberikan karena didapatkan adanya perbedaan makna yang diperoleh oleh partisipan di dalam pengisian alat ukur PTM ini terutama pada dimensi altruism.

\section{Kesimpulan}

Alat ukur Prosocial Tendencies Measure (PTM) versi bahasa Indonesia dapat valid (RMSEA $=0.045$, $\mathrm{CFI}=0.94)$. dan reliable $(\alpha=0.88 \mathrm{I})$ pada anak usia sekolah akhir di Bandung. Meskipun begitu, sebagian besar dimensi masih memiliki reliabilitas yang belum cukup baik (altruism, compliant, emotional, public, dan dire) karena anak usia 9- I 2 tahun cenderung menunjukkan perilaku prososial yang masih belum stabil karena masih berkembangnya sosiokognitif pada anak yang banyak dipengaruhi oleh seberapa banyak pemahaman nilai-nilai yang diterima di lingkungannya.

Saran yang dapat dilakukan untuk penelitian selanjutnya yaitu melakukan perbaikan terhadap itemitem yang masih perlu ditelaah lebih lanjut dalam hal proses perbedaan budaya dan bahasa yang terjadi di Indonesia, terutama pada item I, 8, 22, dan 23 yang memang dari hasil analisis item ditemukan masih perlu untuk diperbaiki agar dapat digunakan dalam alat ukur PTM. Kemudian menelaah kembali item-item dalam dimensi altruism yang dirasa sulit dipahami oleh anak-anak berusia 9-12 tahun dan justru memiliki kemiripan dengan item-item dalam dimensi lain sehingga perlu kembali dilihat bagaimana penyusunan kalimat dalam item-item di dimensi altruism agar menggunakan bahasa yang lebih sederhana dan lebih dapat dipahami oleh anak. Untuk dapat menghasilkan alat ukur yang dapat diinterpretasi terhadap kelompok partisipan yang berbeda dengan menghasilkan hasil validasi yang baik, maka perlu untuk menambahkan bukti-bukti validitas lainnya dan menambahkan jumlah partisipan agar semakin menggambarkan target populasi yang disasar di dalam penelitian.

\section{REFERENSI}

Azimpour, A., Neasi, A., Shehni-Yailagh, M., \& Arshadi, N. (20I2). Validation of "prosocial tendencies measure" in Iranian university students. Journal of Life Science and Biomedicine, 2(2), 34-42.

Carlo, G., \& Randall, B. A. (2002). The development of a measure of prosocial behaviors for late adolescents. Journal of Youth and Adolescence, 3 I (I), 3 I -44. Doi:I 0.I 023/A: 10 I 4033032440

Department of Health and Ageing. (2002). Mental health national outcomes and casemix collection: overview of clinician-rated and consumer self-report measures strengths and difficulties questionnaire (SDQ). Mental Health \& Suicide Prevention Branch, I (50), I-25. http://www.sdqinfo.com.

Ebel, R. L., \& Frisbie, D. A. (I 99I). Essentials of educational measurement (5th Ed). Prentice-Hall. Eisenberg-Berg, N., Cameron, E., Tryon, K., \& Dodez, R. (198I). Socialization of prosocial 
behavior in the preschool classroom. Developmental Psychology, I 7(6), 773-782.

Doi: I 0.1037/00 I2-1649.17.6.773

Eisenberg, N., Fabes, R., \& Spinrad, T. (2006). Prosocial development. Handbook of Child Psychology, 646-702.

Eisenberg, N., Spinrad, T., \& Knafo-Noam, A. (2015). Prosocial development. In M. Lerner, Richard (Ed.), Handbook of Child Psychology and Developmental Science (7th ed., Pp. I-47). John Wiley \& Sons, Inc.

Eisenberg, N. (1 982). The development of prosocial behavior. Academic Press, Inc.

Eisenberg, N., \& Mussen, P. H. (1989). The roots of prosocial behavior in children. Cambridge University Press.

Eisenberg, N., Sallquist, J., French, D. C., Purwono, U., Suryanti, T. A., \& Pidada, S. (2009). The relations of majority - minority group status and having an other-religion friend to Indonesian youths' socioemotional functioning. Developmental Psychology, 45(I ), 248-259. Doi: I 0.1037/a00 I4028

Flouri, E., \& Sarmadi, Z. (2016). Prosocial behavior and childhood trajectories of internalizing and externalizing problems: The role of neighborhood and school contexts. Developmental Psychology, 52(2), 253-258. Doi: I 0.1037/dev0000076

Friedenberg, L. (1995). Psychological testing: design, analysis, and use. Allyn \& Bacon.

Gibbs, J. C., Basinger, K. S., Grime, R. L., \& Snarey, J. R. (2007). Moral judgement development across culture: Revisiting Kohlberg's universality claims. Developmental Review, 27, 443-500.

Goodman, R. (200I). Psychometric properties of the strengths and difficulties questionnaire. Journal of the American Academy of Child and Adolescent Psychiatry, 40(I I), I 337-I345. Doi: I 0.1097/00004583-200I I 1000-000I5

Hair Jr, J. F., Black, W. C., Babin, B. J., \& Andersen, R. E. (20 I4). Multivariate data analysis (MVDA) (Seventh Ed). Pearson New International Edition. Doi: I 0.I 002/978I I I8895238.ch8

Hamonangan, J., \& Ariyanto, A. A. (20I4). Pengaruh eksklusi sosial terhadap kecenderungan prososial: Studi perbandingan antargender. Universitas Indonesia.

Hu, L., \& Bentler, P. M. (1999). Cutoff criteria for fit indexes in covariance structure analysis: Conventional criteria versus new alternatives. Structural Equation Modeling: A Multidisciplinary Journal, 6(I), I-55. Doi: I 0.1080/I07055 I9909540I I8

Kaplan, R. M., \& Saccuzzo, D. P. (2005). Psychological testing: Principles, applications, and issues (6th Ed). Thomson Wadsworth Cengage Learning.

Kementerian Pendidikan dan Kebudayaan Republik Indonesia. (20I6). KBBI daring. Badan Pengembangan \& Pembinaan Bahasa. https://kbbi.kemdikbud.go.id/Beranda

Kementerian Pendidikan dan Kebudayaan Republik Indonesia. (2020). Tesaurus tematis bahasa Indonesia. Badan Pengembangan \& Pembinaan Bahasa. http://tesaurus.kemdikbud.go.id/tematis/

Mestre, M. V., Carlo, G., Samper, P., Tur-Porcar, A. M., \& Mestre, A. L. (20I5). Psychometric evidence of a multidimensional measure of prosocial behaviors for Spanish adolescents. Journal of Genetic Psychology, I 76(4), 260-27I. Doi:I 0.1 080/0022 I325.20I5.1052726

Nantel-Vivier, A., Pihl, R. O., Côté, S., \& Tremblay, R. E. (20I4). Developmental association of prosocial behaviour with aggression, anxiety and depression from infancy to preadolescence. Journal of Child Psychology and Psychiatry and Allied Disciplines, 55( I 0), I I 35-I I 44. Doi: 10.1 I I I/jcpp. 12235

Pastorelli, C., Lansford, J. E., Paula, B., Kanacri, L., Patrick, S., Giunta, L. Di, Bacchini, D., Bombi, A. S., Zelli, A., Miranda, C., Bornstein, M. H., Tapanya, S., Maria, L., Tirado, U., Alampay, L. P., Al-hassan, S. M., Chang, L., \& Deater-deckard, K. (20I6). Positive parenting and children's prosocial behavior in eight countries. Journal of Child Psychology and Psychiatry, 57(7), 824-834. Doi: I 0.1 I I I/jcpp. I 2477

Rayesa, T. F., \& Nu'man, T. M. (20I5). Peranan disipilin induktif orangtua terhadap perilaku prososial yang dimediasi oleh empati. Universitas Islam Indonesia.

Richaud, M. C., Mesurado, B., \& Cortada, A. K. (20I2). Analysis of dimensions of prosocial behavior in an Argentinean sample of children. Psychological Reports: Mental \& Physical Health, I I I (3), 687-696. Doi:I 0.2466/I 0.I I.I 7.PR0.I I I.6.687-696 
Rodrigues, J., Ulrich, N., Mussel, P., Carlo, G., \& Hewig, J. (2017). Measuring prosocial tendencies in Germany: Sources of validity and reliablity of the revised prosocial tendency measure. Frontiers in Psychology, 8(DEC), I-17. Doi: 1 0.3389/fpsyg.20 I7.021 19

Šukys, S., \& Šukienè, E. (20I5). Validity and reliability of the Lithuanian version of prosocial tendencies measure-revised (PTMR). Baltic Journal of Sport \& Health Sciences, 98(3), 43-49. 